
\title{
S Research Square \\ A novel theoretical approach for characterizing pore size distribution of wood cell wall using DSC technique
}

XIANG ZHONG ( $\sim$ ZVita@hotmail.com)

Beijing Forestry University

Erni Ma

Beijing Forestry University

\section{Research Article}

Keywords: wood, cell wall, pore size distribution, differential scanning calorimetry, differential equation

Posted Date: January 25th, 2022

DOI: https://doi.org/10.21203/rs.3.rs-1244993/v1

License: (c) (i) This work is licensed under a Creative Commons Attribution 4.0 International License.

Read Full License 


\section{Abstract}

The pore size distribution of wood cell wall is crucial for wood modification and drying in practice. This study proposed a novel approach to characterize continuous cell wall pore size distribution by solving the differential equation of the water amount melting inside wood obtained from the differential scanning calorimetry (DSC) technique. Compared with the method using the isothermal process, this approach gained a more accurate pore size distribution, and overcome the disadvantages of long-time measurement. Chinese fir (Cunninghamia lanceolata (Lamb.) Hook.) was investigated with this novel method to analyze the cell wall pore size distribution at the fiber saturation point (FSP). The results showed that most pores of the cell wall were below $10 \mathrm{~nm}$. With the increase of pore size, the pore volume decreases sharply, and the cell wall pores above $20 \mathrm{~nm}$ hardly existed. The relation between cell wall pore size and volume had the similar trend between the discontinuous and continuous methods. However, there was a quantity gap in pore volume of 9.4-52.4 times between the two methods.

\section{Introduction}

Wood is a natural cellulosic material with excellent mechanical properties, environmental, acoustic, and aesthetic characteristics. However, wood has inevitable disadvantages such as dimensional instability, flammability, and susceptibility to biodeterioration. These inherent defects need to be overcome by modification before wood utilization.

Wood modification is generally achieved by physically filling the wood porous structure with the modifier or chemically reacting with wood cell wall components, particularly cellulose and hemicellulose (Hill, 2006). In these cases, the pore distribution of wood, especially the pores in the cell wall, plays an important role during the treatment.

However, the cell wall pore distribution is not always constant. Studies have shown that there are huge differences in the cell wall pores with different moisture content (Fengel 1970; Stamm 1967). The water in wood can be divided into two categories, namely free water in the cell lumen and bound water in the cell wall. The interaction between water and cell wall pores mainly comes from the latter, which corresponds to the moisture content below the fiber saturation point (FSP). Since FSP is the turning point of the physical properties of wood, the cell wall pore distribution at this specific moisture content has crucial research significance.

There are various techniques for characterizing wood cell wall pores, such as mercury intrusion porosimetry (Ding et al. 2008; Pfriem et al. 2009; Plötze and Niemz 2011; Zauer et al. 2014a; Peng et al. 2015; Li et al. 2017), nitrogen adsorption method (Papadopoulos et al. 2003; Clair et al. 2008; Chang et al. 2009; Kojiro et al. 2010; Yin et al. 2015, Liang et al. 2019), solvent exclusion method (Flournoy et al. 1991, 1993; Hill et al. 2005; Hui et al. 2009), differential scanning thermoporosimetry (DSCT) (Park et al. 2006a; Dieste et al. 2009; Borrega and Kä renlampi 2011; Grigsby et al. 2013) etc. Each method has its applicable conditions and measurement range. Among these methods, the DSCT can obtain reliable 
results in the study of the cell wall pores at different moisture contents including FSP. The DSCT is based on the phenomenon of the melting-point depression for liquid. That is, in porous materials, the lower pressure at the curved inner surface of the pores results in a decrease in the melting point of the liquid in these pores (Burghoff and Pusch 1979). On the hypothesis that all pores are cylindrical, the relationship between the pore diameter and the melting-point depression could be described by the Gibbs-Thomson equation (Furó and Daicic 1999; Zauer et al. 2014b):

$$
D=-\frac{4 T_{m} \gamma \cos \theta}{\left(T_{m}-T_{m}(D)\right) \rho H_{f}}
$$

1

where $T_{m}$ is the melting temperature, $\gamma$ is the surface tension, $\theta$ is the contact angle, $\rho$ is the density and $H_{f}$ is the specific heat of fusion of water. According to the above principles, Park et al. (2006b) proposed a method based on the isothermal process and used it to discuss the pore distribution of cellulose. However, the method held an additional assumption that the water inside the pores did not melt at very low temperatures, which lead to a relatively large calculation deviation. In addition, the time cost and accuracy of the pore size distribution depend on the setting of the isothermal process. To obtain results in high precision, the testing period of the experiment should be greatly extended.

In this paper, we proposed a novel approach based on differential equations to calculate the pore distribution in wood. This method could greatly improve the accuracy of the results and shorten the test time. At the same time, it needs no additional assumption and thus is more reliable.

\section{Materials And Method}

\section{Experimental materials}

Compared with hardwood, the anatomical structure of softwood is simpler and the variability is less obvious. Therefore, in this study Chinese fir (Cunninghamia lanceolata (Lamb.) Hook.) was utilized to compare the two analytical methods. Chinese fir was sourced from Hebei Province, China. The samples with the size of $5 \mathrm{~mm}(\mathrm{R}) \times 5 \mathrm{~mm}(\mathrm{~L}) \times 1 \mathrm{~mm}(\mathrm{~T})$ were cut from the green sapwood with straight texture and no defect.

The samples were placed in a desiccator in which the relative humidity was kept at $100 \%$ by distilled water at $25^{\circ} \mathrm{C}$. A thermometer was used to detect the relative humidity and temperature. The samples were weighed every day. When the mass change of the samples between two weights was less than $0.02 \%$, the samples were deemed to have reached moisture equilibrium ( $\mathrm{Li}$ and $\mathrm{Ma} 2021$ ).

Pore size distribution calculation

Two pore size distribution calculation methods were used and compared in this study. 
The continuous method proposed in this paper solves the endothermic differential equation of the freezethaw process of water in the wood to obtain the frozen water content of the samples at different temperatures, and then calculate the pore size distribution. During the heating process of the samples in the low-temperature state, the heat absorbed by the samples is divided into two parts: sensible heat and latent heat. Sensible heat is the heat required to increase the temperature of the substance, including the substance of wood cell wall, the frozen water in the pores, and the unfrozen water. Note that the air in the sample was not included in this study. Latent heat is the heat required for the phase change of frozen water in pores of different sizes. Based on the above, the heat absorption can be expressed by Eq. (2):

$$
\Delta H=m_{C W} C_{C W} \Delta T+m_{f W} c_{i} \Delta T+\left(m_{W}-m_{f W}\right) c_{W} \Delta T-H_{f} \Delta m_{f W}
$$

where $\Delta T$ is the difference in temperature $\left({ }^{\circ} \mathrm{C}\right) ; \Delta H$ is the heat absorption corresponding to the temperature change $(\mathrm{mJ}) ; m_{C w^{p}} m_{f W^{r}}$ and $m_{W}$ are the mass of wood cell wall substance, frozen water, and total water in the samples respectively $(\mathrm{mg}) ; C_{C W} C_{W}$ and $C_{i}$ are the specific heat capacities of wood cell wall, water and ice, respectively $\left(\mathrm{J}^{\circ} \mathrm{C}^{-1} \mathrm{~g}^{-1}\right) ; \Delta m_{f w}$ is the melting amount of frozen water corresponding to temperature changes $(\mathrm{mg}) ; H_{f}$ is the specific heat of fusion of pure water $\left(\mathrm{J} \mathrm{g}^{-1}\right)$.

Frozen water in wood was assumed to behave like pure water, thus the accepted value of $333.6 \mathrm{~J} \mathrm{~g}^{-1}$ was used (Repellin and Guyonnet 2005; Dieste et al. 2009).

Differentiate the time on both sides of Eq. (2) to obtain Eq. (3):

$$
\frac{d H}{d t}=m_{C W} C_{C W} \lambda+m_{f W}\left(c_{i}-c_{W}\right) \lambda+m_{W} C_{W} \lambda-H_{f} \frac{\mathrm{d} m_{f W}}{\mathrm{~d} T} \lambda
$$

where $\lambda$ is the rate of temperature change, that is, $\mathrm{d} T / \mathrm{d} t$, and $t$ represents the time; $\frac{d H}{d t}$ refers to the time rate of change of heat absorption, that is, heat flow, which can be expressed as a function of temperature; $\frac{\mathrm{d} m_{f w}}{\mathrm{~d} T}$ represents the rate of change of frozen water content concerning temperature and it is also a function of temperature. Thus Eq. (4) can be obtained by organizing Eq. (3):

$$
\frac{\mathrm{d} m_{f W}(T)}{\mathrm{d} T}-\frac{C_{i}-C_{W}}{H_{f}} m_{f W}(T)=-\frac{1}{\lambda H_{f}} \frac{\mathrm{d} H}{\mathrm{~d} t}(T)-\frac{m_{C W} C_{C W}+m_{W} C_{W}}{H_{f}}
$$

4

Obviously, Eq. (4) is a non-homogeneous first order linear differential equation for frozen water content $m_{f w}$ with respect to temperature $T$. Solving Eq. (4) can obtain the frozen water content as a function of temperature $m_{f W}(T)$ : 


$$
m_{f W}(T)=\frac{1}{\lambda H_{f}} e^{\frac{c_{i}-c_{W}}{H_{f}}} T \int_{T}^{0} \frac{\mathrm{d} H}{\mathrm{~d} T}(T) e^{-\frac{c_{i}-c_{W}}{H_{f}}} T \mathrm{~d} T+\frac{m_{C W} C_{C W}+m_{W} C_{W}}{C_{i}-C_{W}}+C e^{\frac{c_{i}-c_{W}}{H_{f}}} T
$$

Since the heat flow function is not clear, the DSC measurement data can be used to calculate the numerical solution of the equation instead of the analytical solution. And it is acceptable that when the temperature is $0^{\circ} \mathrm{C}$, there is no frozen water in the wood sample (i.e., when $T=0$, then $m_{f W}(T)=0$ ). Considering this condition into the Eq. (5) can easily obtain the value of the constant $C$ :

$$
C=-\frac{m_{C W} C_{C W}+m_{W} C_{W}}{C_{i}-C_{W}}
$$

6

There is $m_{C W} C_{C W}+m_{W} C_{W}$ in both Eq. (5) and Eq. (6), which just represents the heat capacity of the samples at a specific state when no water is frozen, and thus it can be easily measured at a temperature above $0^{\circ} \mathrm{C}$. Finally, the pore size distribution $\frac{d V}{d D}$ of the samples is derived from the relationship between the content of frozen water and the temperature in Eq. (7).

$$
\frac{d V}{d D}=\frac{\left|d V_{f W}\right|}{d D}=\frac{d\left|m_{f W} / \rho_{f W}\right|}{d D}=-\frac{1}{\rho_{f W}} \cdot \frac{d m_{f W}}{d T} \cdot \frac{d T}{d D}
$$

7

where $V_{f W}$ is the volume of frozen water $\left(\mathrm{cm}^{3}\right) ; \rho_{f W}$ is the density of frozen water $\left(\mathrm{g} \mathrm{cm}^{-3}\right)$, the value of $0.9 \mathrm{~g} \mathrm{~cm}^{-3}$ (the density of ice) was used in this study; $\frac{d m_{f w}}{d T}$ and $\frac{d T}{d D}$ can be derived from the Eq. (5) and (1), respectively.

The discontinuous method was performed as a comparison which took an isothermal step method according to Park et al. (2006b) as well as Zauer et al. (2014b). Pore size distribution was determined by measuring the amount of water that has its melting temperature depressed at each isothermal step. If the frozen water does not melt in the first heating step, the sensible heat can be calculated based on the heat absorption of this step, and the latent heat of melting in the subsequent steps is calculated by subtracting the sensible heat from the total heat:

$$
H_{i}=H_{t, i}-C_{s} \Delta T
$$

$$
m_{f W, i}=\frac{H_{i}}{H_{f}}
$$


where $H_{i}$ is the latent heat of water at each step (J); $H_{t, i}$ is the total heat absorption at each step (J); $C_{S}$ is the specific heat capacity of the samples $\left(\mathrm{J}^{\circ} \mathrm{C}^{-1}\right) ; m_{f W, i}$ is the mass of frozen water at each step $(\mathrm{g})$.

In summary, there are the following differences between the continuous method and discontinuous method: 1) The continuous method uses a continuous measurement procedure, during which no isothermal stage is required, thus a continuous pore size distribution could be acquired, while the discontinuous method uses an intermittent measurement procedure, and the obtained pore size distribution is discontinuous. Therefore, the former can make better use of the measured data, and greatly reduce the measuring time. 2) The discontinuous method assumes that the specific heat of the samples does not change in the early stage of the experiment, which may cause errors. In the contrast, the continuous method does not require this assumption, thus it is possible to achieve more theoretical accuracy.

DSC measurement

TA Company's DSC-Q2000 instrument was employed for the freeze-thaw test. The samples were cut to a chip with a diameter of about $4 \mathrm{~mm}$ and put in an aluminum pan for sealing. Each sample was cooled to $-30^{\circ} \mathrm{C}$ and maintained for 5 minutes to ensure that the water in the sample was fully frozen. Due to the different principles of continuous method and discontinuous method as mentioned above, two different DSC heating programs were taken:

Continuous method: The temperature rose to $0^{\circ} \mathrm{C}$ at a constant rate of $2^{\circ} \mathrm{C} \mathrm{min}-1$, maintained for 3 minutes, and then continued to rise to $10^{\circ} \mathrm{C}$ at the same rate. This measurement took 23 minutes in total.

Discontinuous method: The temperature rose step by step to $-21,-11.6,-7.3,-5.4,-4.2,-2.8,-2,-1.3-0.8^{\circ} \mathrm{C}$ at a rate of $2{ }^{\circ} \mathrm{C} \mathrm{min}^{-1}$, and maintained to return the heat flow to the baseline in each step, and finally continued to rise to $10^{\circ} \mathrm{C}$ at the same rate. This process took about 45 minutes. The pore diameters corresponding to different temperatures calculated by the Eq. (1) are shown in Table 1. 
Table 1

The pore diameters corresponding to

different temperatures.

\begin{tabular}{|ll|}
\hline Temperature $\left({ }^{\circ} \mathrm{C}\right)$ & Pore diameter $(\mathrm{nm})$ \\
\hline-21 & 1.9 \\
\hline-11.6 & 3.4 \\
\hline-7.3 & 5.4 \\
\hline-5.4 & 7.3 \\
\hline-4.2 & 9.4 \\
\hline-2.8 & 14.1 \\
\hline-2 & 19.8 \\
\hline-1.3 & 30.5 \\
\hline-0.8 & 49.5 \\
\hline
\end{tabular}

Generally, a slower heating rate and lower sample mass can lead to more accurate enthalpy measurements (Simpson and Barton 1991). However, if the heating rate is too low, the measured signal will show noise and it is difficult to perform the repeatable results. Therefore, a heating rate of $2{ }^{\circ} \mathrm{C} \min ^{-1}$ was used in this study (Zauer et al. 2014b).

After the measurement, the samples were taken out from the aluminum pan, placed in an oven to be dried at $103{ }^{\circ} \mathrm{C}$ for 8 hours, and the oven-dry mass was weighed, and the moisture content of the samples was calculated.

\section{Results And Discussion}

Figure 1 shows the change process of the frozen water content calculated by the Eq. (5) with increasing temperature. The figure indicates that as the temperature increases, the frozen moisture content inside the wood samples decreases linearly until around $0^{\circ} \mathrm{C}$. In the range very close to $0^{\circ} \mathrm{C}$, since the temperature is close to the melting point of bulk water, the water inside the samples melts faster, so the frozen water content shows an accelerated downward trend. When the temperature rises to $0^{\circ} \mathrm{C}$, the calculated frozen water content is equal to zero, which depends on two idealized conditions: 1) There is no free water in the cell cavity or other large voids inside the samples, that is, all water is present in the cell wall; 2) There is no signal delay in the endothermic data measured by the DSC instrument. However, these conditions are difficult to fully meet in reality, which will lead to an error.

The dashed horizontal line in Fig. 1 represents the total water content of the test samples obtained by weighing after drying. Therefore, the difference between the dashed line and the solid line shows the unfrozen water (or melted bound water) content inside the samples. The unfrozen water increases as the 
temperature rises, and when the temperature reaches $0^{\circ} \mathrm{C}$, the value is equal to the total water content of the samples.

Due to the limitation of the Gibbs-Thomson equation, the measurement of sample pores is effectively applicable to the pore size range above $2 \mathrm{~nm}$, corresponding to the temperature higher than $-20^{\circ} \mathrm{C}$ (Jähnert et al. 2008). However, even at $-20^{\circ} \mathrm{C}$, it is observed that the frozen water content is not equal to the total water content, which means that at this temperature, there is indeed non-freezing water in the wood samples, which agrees with Telkki, Ylinemi and Jokisaari (2013).

The mesopore pore size distribution of wood cell walls calculated according to Eq. (7) is shown in Fig. 2. In the small pore diameter range, $\mathrm{dV} / \mathrm{dD}$ has a very high value. Within the pore diameter range below 10 $\mathrm{nm}$, the curve shows a great fluctuation, which may be attributed to the variability of cell wall pores in this range and the noise of the DSC signal. According to Eq. (1) and (7), in this small pore range, even a slight difference in pore diameter will result in a large change in the melting temperature, which makes $\mathrm{dV} / \mathrm{dD}$ highly sensitive to signal noise. As the pore diameter increases, $d V / d D$ decreases rapidly, and $d V / d D$ is very close to zero with subtle variability in the pore diameter range above $20 \mathrm{~nm}$. The pores within $10 \mathrm{~nm}$ account for most of the cell wall pores, which is in consistent with the results of previous studies (Hill 2006; Yin et al. 2015).

The discontinuous method was conducted as a comparison, and the result is shown in Fig. 3. Since this method used piecewise integration to calculate the sample enthalpy changes at different temperature ranges, the results are demonstrated in histograms. To compare the results of the two methods intuitively, data in Fig. 2 are grouped and integrated with the same pore diameter range, and the results are also displayed in Fig. 4 as histograms. Comparing the pore size distribution between Fig. 3 and Fig. 4, it is evident that the trends of these two methods are generally similar. The pore volume is the largest in the range of 1.9-3.4 nm. With the increase of pore diameter, the pore volume gradually decreases. Only a tiny increase appears in the range of 9.4-14.1 nm.

However, the overall pore volume obtained by the method of discontinuous integration (Fig. 3 ) is significantly smaller than that of the continuous method (Fig. 4). For better comparison of the pore volume obtained by the two methods, the ratio of the continuous method and discontinuous method was calculated and shown in Fig. 5 . In the range of $30.5-49.5 \mathrm{~nm}$, the pore volume obtained by the continuous method is 9.4 times that of the discontinuous method, while in the range of 1.9-3.4 nm, is 52.4 times. The discontinuous method assumes that no water in the sample melts at the initial stage of the measurement, but the water behavior at this stage is actually not clear. Since the latent heat of water melting is much higher than the specific heat capacity of frozen water, even if only a small amount of frozen water melts, it will result in higher heat absorption. This will cause the measurement of sensible heat to be too high, and underestimate the latent heat in each subsequent stage, therefore undervalue the amount of melting water. In addition, another consequence of this assumption is that the melting water in large pores is overestimated. As the temperature increases, the water in the samples continues to melt, and since the specific heat capacity of water is twice that of ice, the sensible heat of the samples also 
continues to increase. However, when calculating the latent heat in later stages, only the lower sensible heat value in the initial stage is considered and subtracted from total heat absorption, which leads to an overestimation of the latent heat, and this error will become more serious as the temperature rises.

Therefore, the decrease in pore volume in the range of larger pore diameter in Fig. 3 is not as obvious as in Fig. 4, which can also be reflected in Fig. 5.

Replace $C_{W}$ in the Eq. (4) with $C_{i}$ to obtain a simplified equation to roughly simulate the impact of the above assumption. The results are still given in the form of a histogram in Fig. 6 . The pore volume in Fig. 6 and its change trend has become close to the result in Fig. 3, which confirms that this assumption is an important factor for the difference in the calculation results between the two methods.

\section{Conclusions}

This study proposed a continuous method based on the differential equation combined with the DSC technique to calculate the pore size distribution of the cell wall of Chinese fir at FSP. The results showed that most wood cell wall pores were less than $10 \mathrm{~nm}$, and as the pore diameter increased, the differential pore volume decreased sharply. The pore size distribution calculated by the continuous method was more reliable than the discontinuous method in the earlier report because it required no additional assumptions. In addition, since there was no need to set an isothermal step during the experiment, this method could greatly reduce the testing time while obtaining a continuous pore size distribution. The decreasing trend of pore volume with pore diameter obtained by the two methods was similar. However, the quantitative analysis of the two methods was quite different. Specifically, the pore volume calculated by the continuous method was 9.4-52.4 times larger than that derived by the discontinuous method.

To simplify the calculation, several parameters in this study adopt theoretical values (such as the specific heat capacity of water and ice in the cell wall pores), which may lead to subtle calculation errors. In future research, the exploration of the physical properties of the internal substances of wood could be considered to obtain more accurate calculation parameters. In addition, further study on pore distribution of wood cell wall at different moisture content by the continuous method could be expected.

\section{Declarations}

\section{Conflict of interest}

The authors declare that they have no known competing financial interests or personal relationships that could have appeared to influence the work reported in this paper.

\section{Acknowledgement}

The authors acknowledge the National Natural Science Foundation of China (31971583) for financial support. We also acknowledge the assistance of Jing-Yu Li for revising this paper. 


\section{References}

1. Burghoff HG, Pusch W (1979) Characterization of water structure in cellulose acetate membranes by calorimetric measurements. J Appl Polym Sci 23(2):473-484

2. Borrega M, Karenlämpi, PP (2011) Cell wall porosity in Norway spruce wood as affected by hightemperature drying. Wood Fiber Sci 43(2):206-214

3. Chang SS, Clair B, Ruelle J et al (2009) Mesoporosity as a new parameter for understanding tension stress generation in trees. J Exp Bot 60(11):3023-3030

4. Clair B, Gril J et al (2008) Characterisation of a gel in the cell wall to elucidate the paradoxical shrinkage of tension wood. Biomacromolecules 9(2):494-498

5. Dieste A, Krause A, Mai C et al (2009) Modification of Fagus sylvaticaL. with 1,3-dimethylol-4,5dihydroxy ethylene urea (DMDHEU). Part 2: Pore size distribution determined by differential scanning calorimetry. Holzforschung 63:89-93

6. Ding WD, Koubaa A, Chaala A et al (2008) Relationship between wood porosity, wood density and methyl methacrylate impregnation rate. Wood Mater Sci Eng 3(1-2):62-70.

7. Fengel D (1970) The ultrastructure of cellulose from wood - Part 2: Problems of the isolation of cellulose. Wood Sci Technol 1(4):15-35

8. Flournoy DS, Kirk TK, Highley TL (1991) Wood decay by brown-rot Fungi: Changes in pore structure and cell wall volume. Holzforschung 45(5):383-388

9. Flournoy DS, Paul JA, Kirk TK et al (1993) Changes in the size and volume of pores in sweetgum wood during simultaneous rot by Phanerochaete chrysosporium Burds. Holzforschung 47(4):297301

10. Furó I, Daicic J (1999) NMR cryoporometry: A novel method for the investigation of the pore structure of paper and paper coatings. Nord Pulp Pap Res J 14(3):221-225

11. Grigsby WJ, Kroese H, Dunningham EA (2013) Characterisation of pore size distributions in variously dried Pinus radiata: analysis by thermoporosimetry. Wood Sci Technol 47(4):737-747

12. Hill CAS, Forster SC, Farahani M et al (2005) An investigation of cell wall micropore blocking as a possible mechanism for the decay resistance of anhydride modified wood. Int Biodeter Biodegr 55(1):69-76

13. Hill CAS (2006) Wood modification: chemical, thermal and other process. Chichester, Wiley

14. Hui L, Liu Z, Ni Y (2009) Characterization of high-yield pulp (HYP) by the solute exclusion technique. Bioresource Techno 100(24):6630-6634

15. Jähnert S et al (2008) Melting and freezing of water in cylindrical silica nanopores. Phys Chem Chem Phys 10(39):6039-6051

16. Kojiro K, Miki T, Sugimoto H, Nakajima M, Kanayama K (2010) Micropores and mesopores in the cell wall of dry wood. J Wood Sci 56(2):107-111 
17. Li JY, Ma EN (2021) Influence of heat treatment and delignification on hygroscopicity limit and cell wall saturation of southern pine wood. Journal of Forestry Engineering 6(3):61-68

18. Li L, Wang X, Yan Y et al (2017) Pore analysis of thermally compressed Scots pine (Pinus sylvestris L.) by mercury intrusion porosimetry. Holzforschung 72(1):57-63

19. Liang R, Zhu YH, Wen L et al (2019) Exploration of effect of delignification on the mesopore structure in poplar cell wall by nitrogen absorption method. Cellulose 27(4):1921-1932

20. Papadopoulos AN, Hill CAS, Gkaraveli A (2003) Determination of surface area and pore volume of holocellulose and chemically modified wood flour using the nitrogen adsorption technique. Holz Roh Werkst 61(6):453-456

21. Park S, Venditti RA, Abrecht DG et al (2006a) Surface and pore structure modification of cellulose fibers through cellulase treatment. J Appl Polym Sci 103(6):3833-3839

22. Park S, Venditti RA, Jameel $\mathrm{H}$ et al (2006b) Changes in pore size distribution during the drying of cellulose fibers as measured by differential scanning calorimetry. Carbohyd Polym 66(1):97-103

23. Peng L, Wang D, Fu F, Song B (2015) Analysis of wood pore characteristics with mercury intrusion porosimetry and X-ray micro-computed tomography. Wood Res-Slovakia 60(6):857-864

24. Pfriem A, Zauer M, André W (2009) Alteration of the pore structure of spruce (Picea abies (L.) Karst.) and maple (Acer pseudoplatanus L.) due to thermal treatment as determined by helium pycnometry and mercury intrusion porosimetry. Holzforschung 63(1):94-98

25. Plötze M, Niemz P (2011) Porosity and pore size distribution of different wood types as determined by mercury intrusion porosimetry. Eur J Wood Wood Prod 69(4):649-657

26. Repellin V, Guyonnet R (2005) Evaluation of heat-treated wood swelling by differential scanning calorimetry in relation to chemical composition. Holzforschung 59(1):28-34

27. Simpson LA, Barton A (1991) Determination of the fibre saturation point in whole wood using differential scanning calorimetry. Wood Sci Technol 25(4):301-308

28. Stamm AJ (1967) Movement of fluids in wood - Part I: Flow of fluids in wood. Wood Sci Technol 1(2):122-141.

29. Telkki VV, Ylinemi M, Jokisaari J (2013) Moisture in softwoods: fiber saturation point, hydroxyl site content, and the amount of micropores as determined from NMR relaxation time distributions. Holzforschung 67(3):291-300

30. Yin J, Song K, Yun L et al (2015) Comparison of changes in micropores and mesopores in the wood cell walls of sapwood and heartwood. Wood Sci Technol 49(5):987-1001

31. Zauer M, Hempel S, Pfriem A et al (2014a) Investigations of the pore-size distribution of wood in the dry and wet state by means of mercury intrusion porosimetry. Wood Sci Technol 48(6):1229-1240

32. Zauer $\mathrm{M}$, Kretzschmar $\mathrm{J}$ et al (2014b) Analysis of the pore-size distribution and fiber saturation point of native and thermally modified wood using differential scanning calorimetry. Wood Sci Technol 48:177-193 
Figures

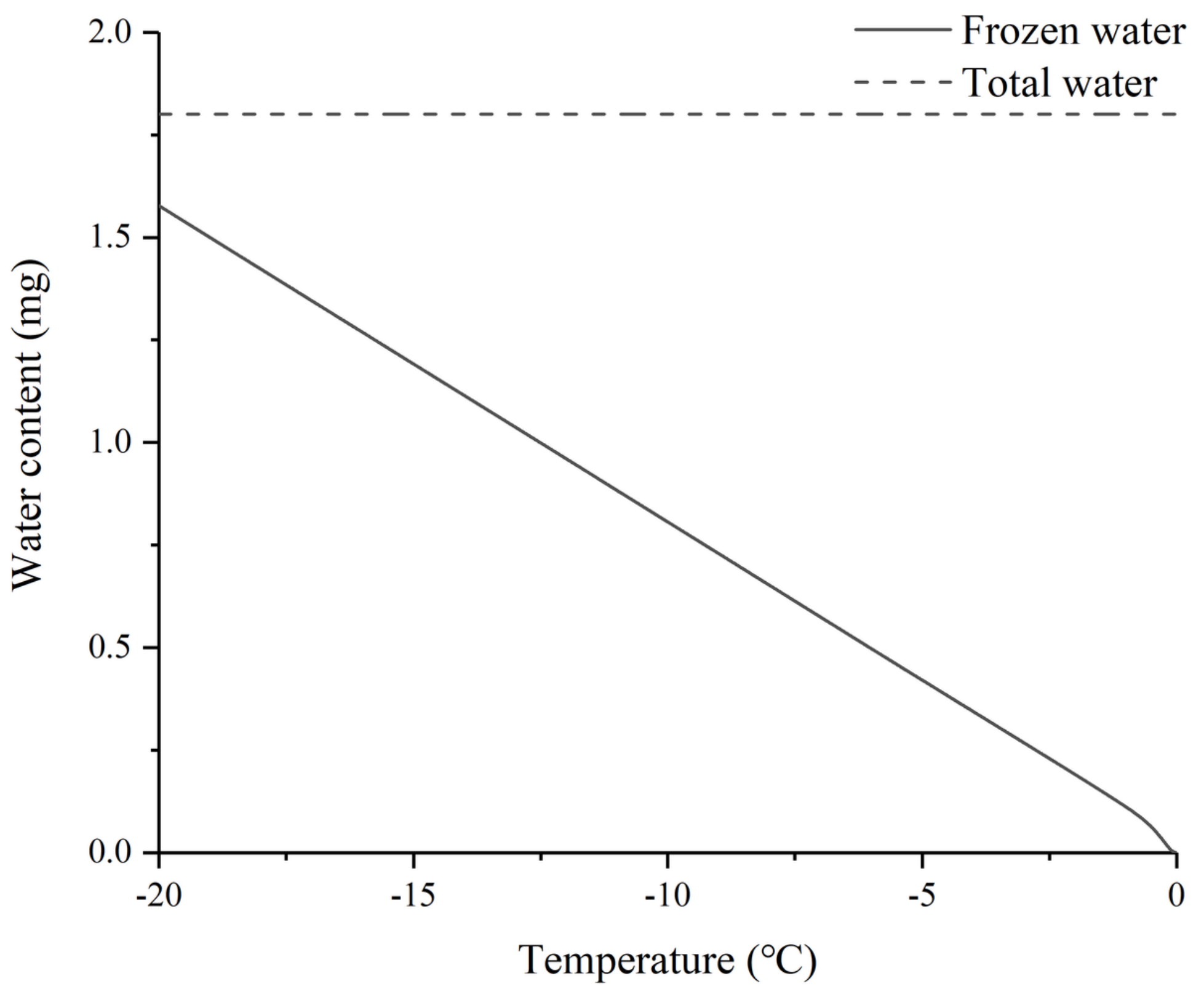

Figure 1

The water content of the samples with increasing temperature. The solid line and the dashed line indicate the frozen water content and the total water content, respectively. 


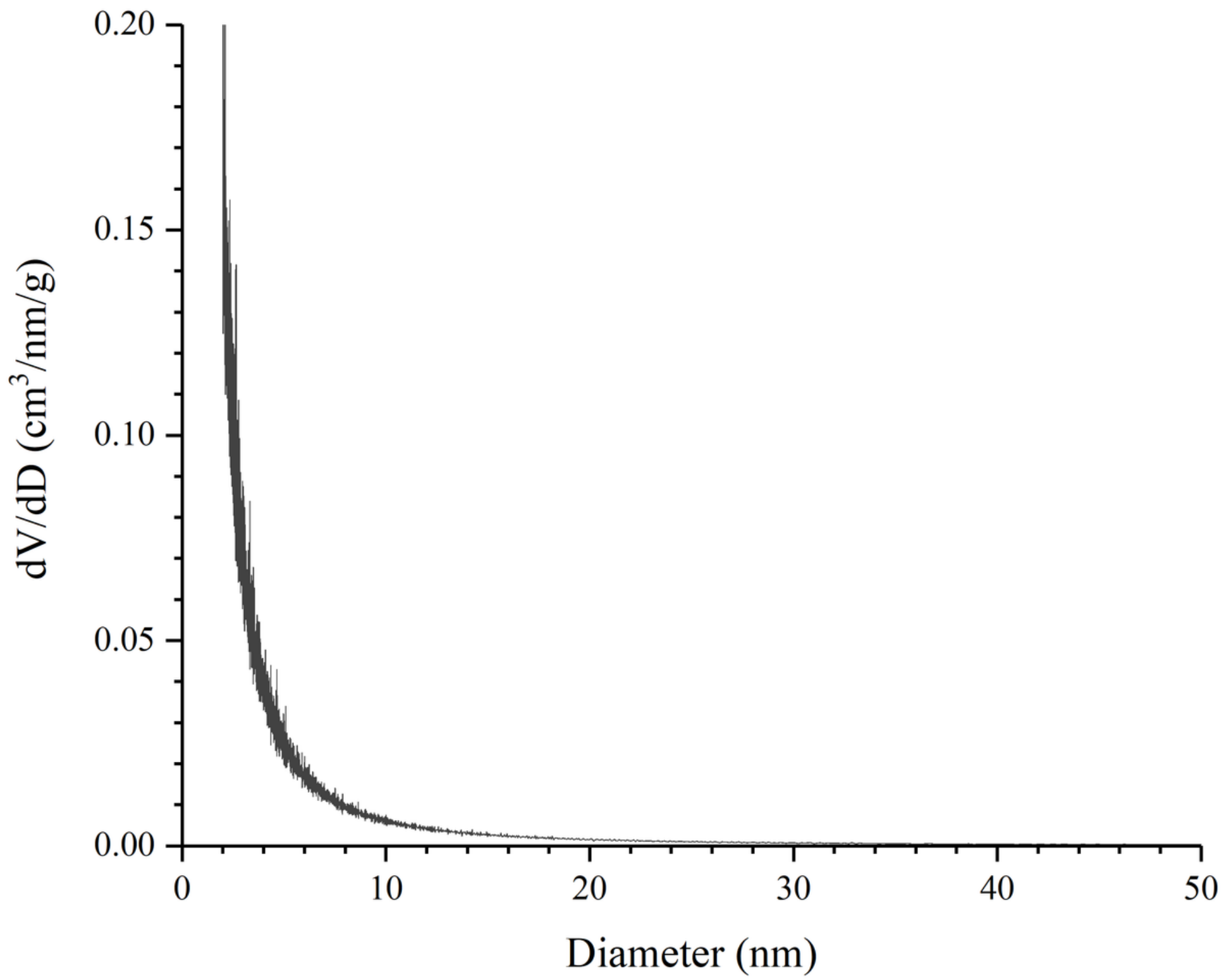

Figure 2

The mesopore pore size distribution of wood cell walls calculated according to the continuous method. 


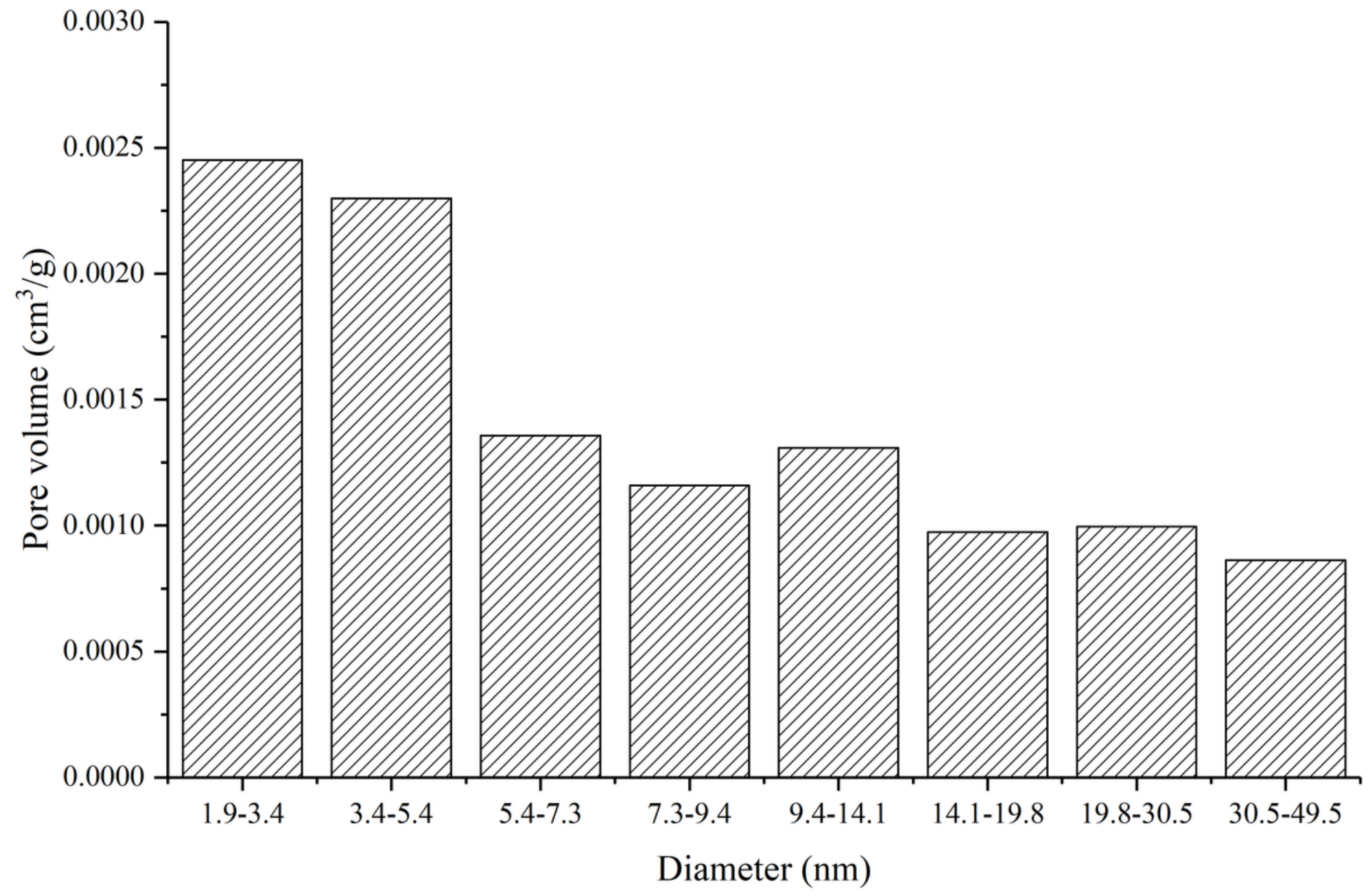

Figure 3

The pore size distribution measured by the discontinuous method. 


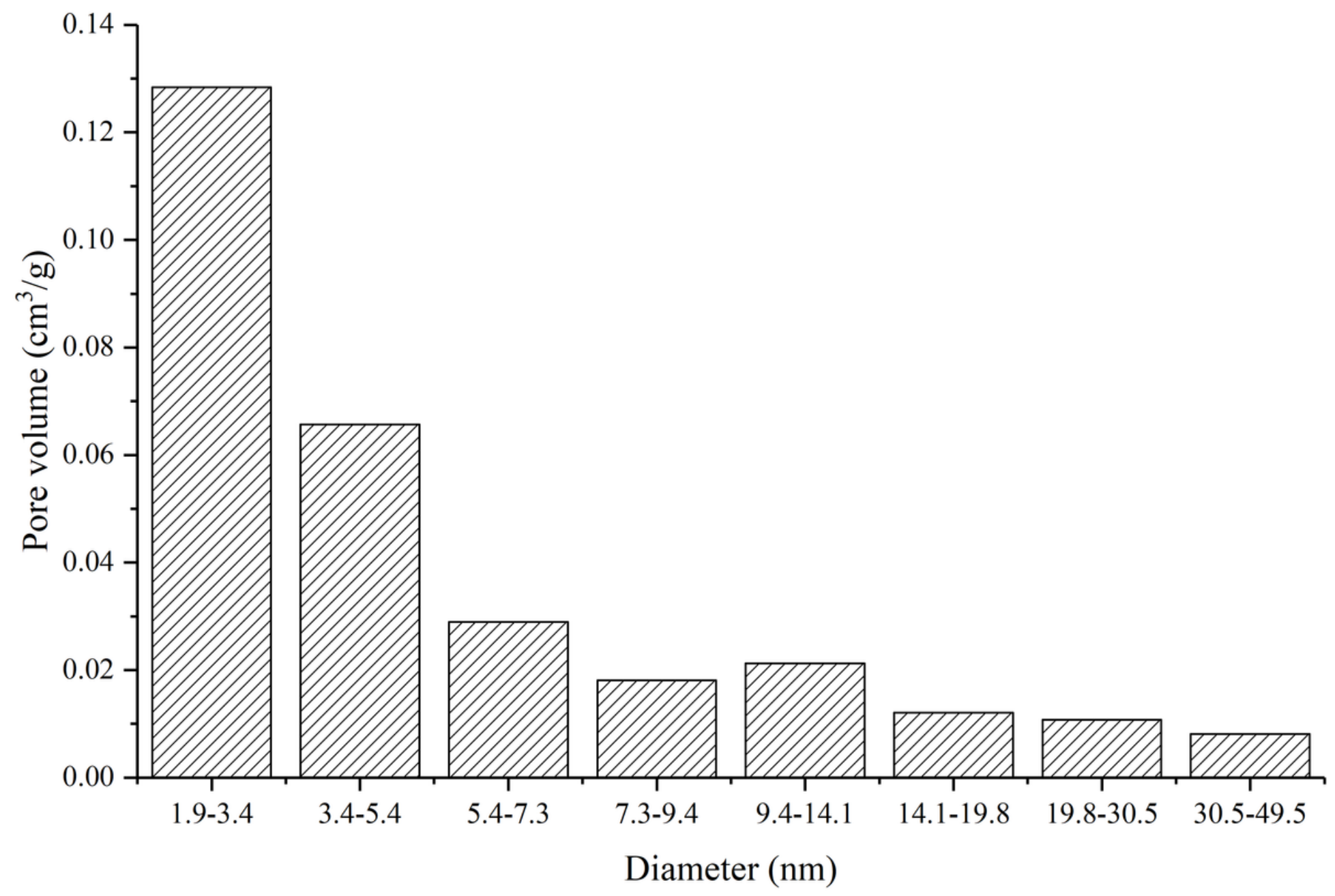

Figure 4

The pore size distribution measured by the continuous method using histograms. 


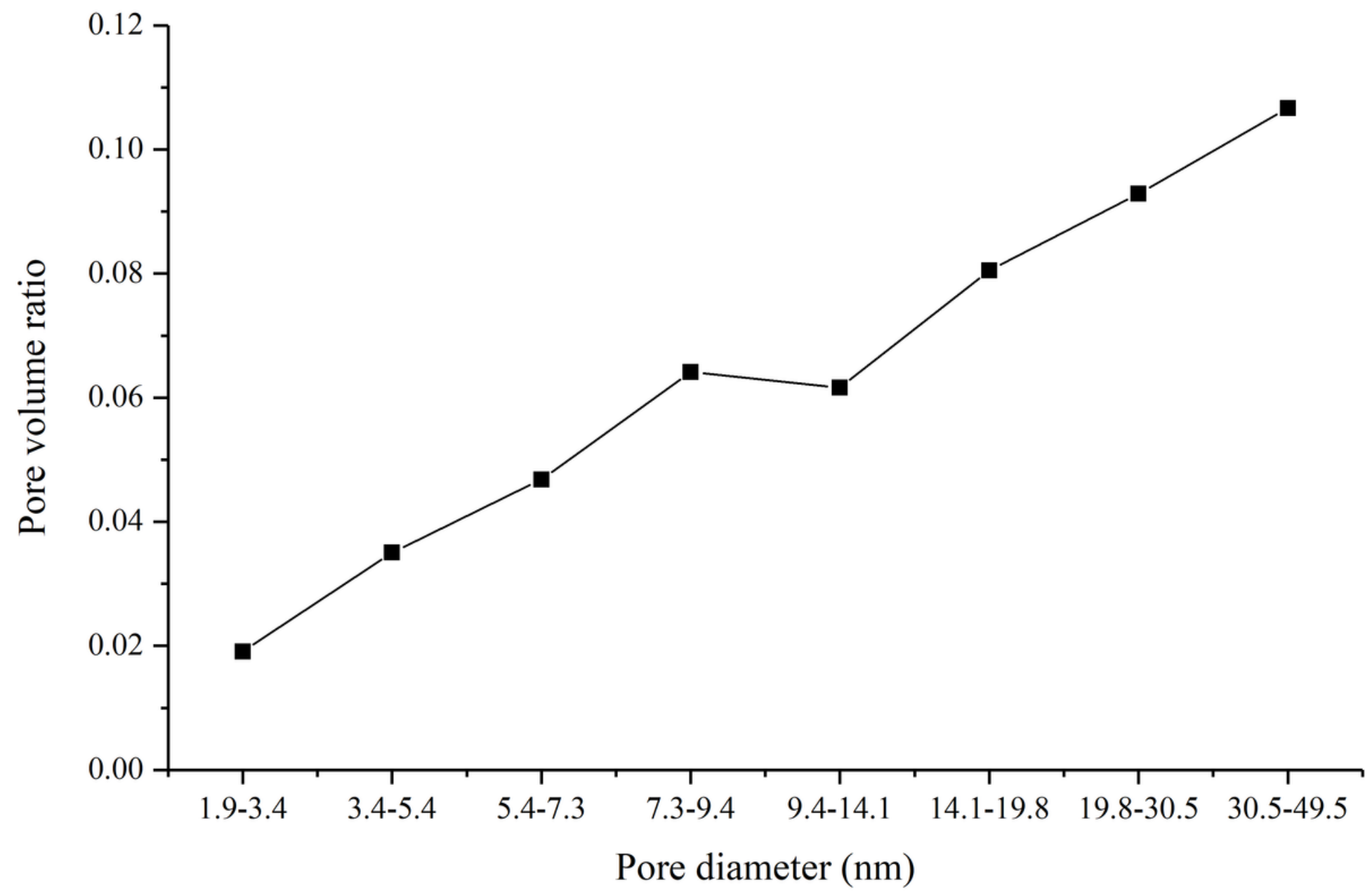

Figure 5

The ratio of the pore volume of the discontinuous method and continuous method in each pore diameter range. 


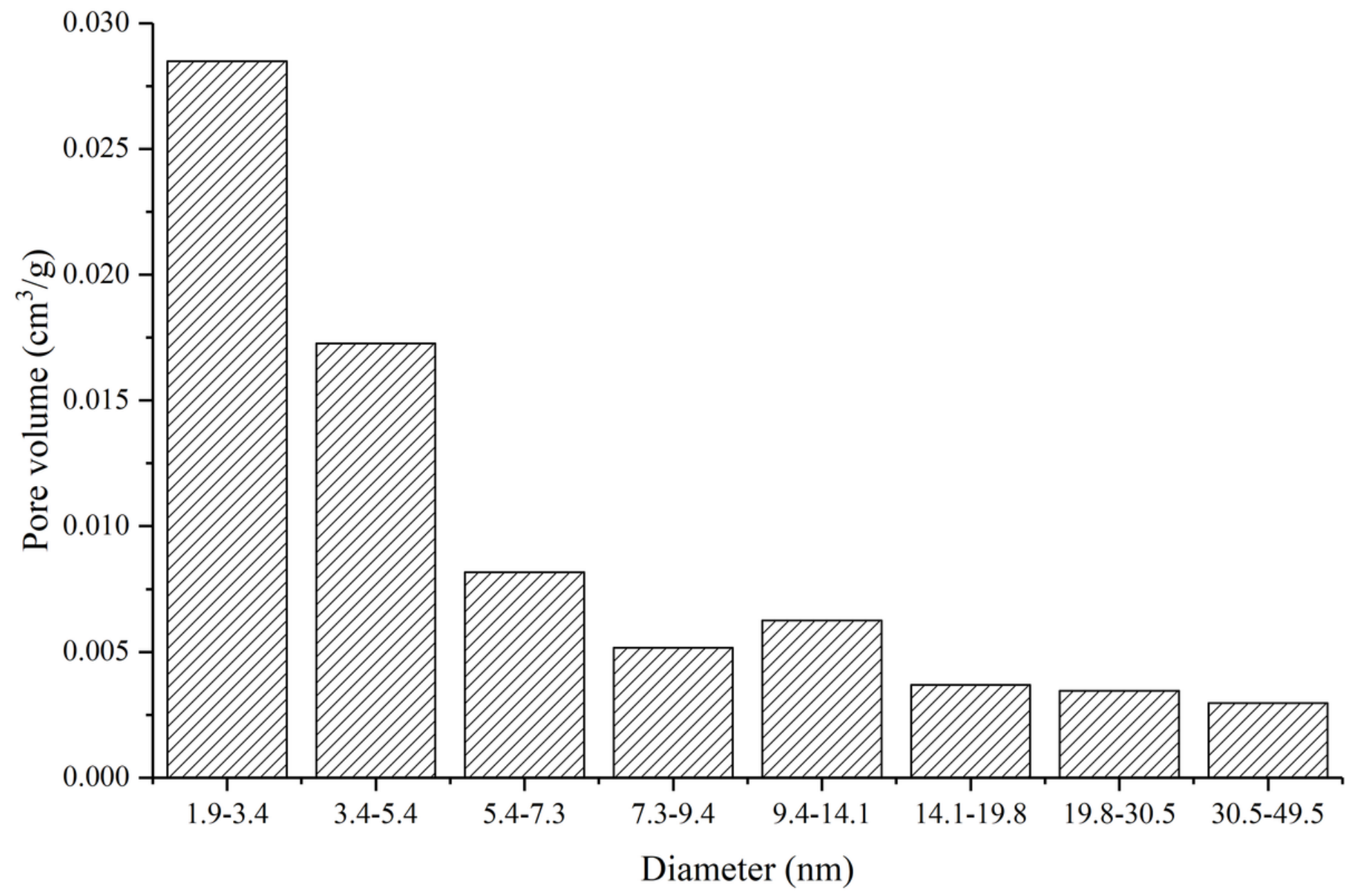

Figure 6

The pore size distribution measured by the simplified continuous method using histograms. 